\title{
PROFESI \\ PENDIDIKAN DASAR
}

\section{INVESTIGASI MINAT BELAJAR TERHADAP MODUL ELEKTRONIK BERBASIS ETNOKONTRUKTIVISME}

\author{
Agung Rimba Kurniawan ${ }^{1)}$, Hendra Budiono ${ }^{2)}$, Ahmad Hariandi ${ }^{3)}$, Marlina ${ }^{4)}$, Eka Feri \\ Kurniawati $^{5)}$, Rizka Meidiawati ${ }^{6}$, Suci Okta Piyana ${ }^{7)}$
1,2,3,4,5,6,7) Fakultas Keguruan dan Ilmu Pendidikan, Universitas Jambi ${ }^{1}$ unesa.agung@yahoo.com ; ${ }^{2}$ hendra.budiono@unja.ac.id ; ${ }^{3}$ ahmad.hariandi@unja.ac.id; ${ }^{4}$ marlinapgsd2018@gmail.com ; ${ }^{5}$ ekaferi99@gmail.com ; ${ }^{6}$ rizkameidiawati91@ gmail.com; ${ }^{7}$ suci.okta.piyana@gmail.com

\begin{abstract}
The purpose of this study is to investigate student interest in learning the electronic module ethnoconstructivism in several elementary schools. The method used in this research is descriptive quantitative. The results of the research carried out at Muara Bulian Elementary School No. 13 / I with the highest frequency 31 with a percentage of $54.4 \%$ included in the Good category. Whereas in SD Negeri No. 80 / I Muara Bulian with the most frequency 31 with a percentage of $49.2 \%$ included in the category of Very Good. Based on these results a T test was performed with a Sig. (2-Tailed) value of 0.683>0.05, so there were no significant comparisons or differences in the learning interests of fifth grade students at SD Negeri 13 / I Muara Bulian with students at SD Negeri No. 80 / I Muara Bulian.
\end{abstract}

Keywords: interest, electronic module, student, learning

\section{PENDAHULUAN}

Pendidikan adalah sebuah proses memperbaiki kualitas kehidupan, serta memperoleh dan menanamkan keterampilan yang dilakukan oleh siswa. Pendidikan adalah kegiatan yang sangat penting bagi manusia, dengan keberadaan pendidikan manusia, dapat mengubah perilaku dan pengetahuan menjadi lebih baik (Astalini, Kurniawan, Perdana, \& Pathoni, 2019). Pendidikan itu sendiri mempunyai tujuan untuk mengembangkan potensi yang terdapat pada perseta didik, agar dapat berfikir secara kritis dan kreatif (Rusman, 2014). Pendidikan mempunyai peranan yang sangat penting dalam menjamin kelangsungan hidup negara, hal ini dikarenakan pendidikan merupakan sarana untuk meningkatkan dan mengembangkan kualitas sumber daya manusia. Pendidikan yang baik akan mampu menghasilkan sumber daya manusia yang produktif, kreatif, afektif, dan inovatif. Education is an ongoing process that aims to increase the quality of human resources (Darmaji, Kurniawan, \& Suryani, 2019). Ini menunjukkan bahwa dengan adanya pendidikan dapat meningkatkan kualitas anak bangsa. 
Pendidikan pada dasarnya adalah usaha sadar untuk mengembangkan potensi siswa. Pendidikan di masa sekarang sangat membutuhkan penggunaan teknologi untuk meningkatkan kompetensi peningkatan sumber daya manusia. karena sekarang adalah era revolusi industri 4.0 (Astalini, Kurniawan, Sulistiyo,\& Perdana, 2019). Revolusi industri 4.0 tidak hanya membuka jalan bagi kegiatan ekonomi tetapi juga memberikan peluang bagi pendidikan melalui teknologi pembelajaran. Belajar teknologi yaitu untuk tumbuh seiring dengan perkembangan zaman.

Dalam meningkatkan mutu pendidikan perlu ditingkatkan adanya pembaharuan di bidang Pendidikan untuk saling bertukar informasi satu sama lain. The success of the learning process is influenced by the quality and way of teaching a teacher (Darmaji, Kurniawan, Suryani, \& Lestari, 2018). Oleh karena itu, Proses pembelajaran perlu adanya interaksi antara siswa dan guru dari sumber belajar pada suatu lingkungan belajar. Sebagai pengajar atau pendidik, guru merupakan salah satu faktor penentu keberhasilan.

Menurut Ardana (2019), tugas guru adalah: (1) Membimbing siswa dalam menemukan prestasi apa yang mereka cari dalam pembelajaran dan dapat mewujudkan dalam kehidupan mereka sehari-hari dan diharapkan agar guru dapat berpartisipasi pada semua siswa; (2) mengurangi ceramah di depan kelas. Dalam kelas guru hendaknya tidak hanya menceramahmi siswa saat menjelaskan, tapi mempersilahkan para siswa belajar menemukan sendiri apa yang mereka gali lewat pembelajaran. Oleh karena itu, guru memiliki tanggung jawab yang besar untuk kualitas kepribadian pelajar.

Kemajuan teknologi yang semakin canggih dalam pendidikan dapat dimanfaatkan oleh guru untuk mengembangkan media pembelajaran berupa bahan ajar yang berbentuk modul elektronik. E-module to be one of learning media that can motivate student learning (Darmaji et.al, 2019). Oleh karena itu, dengan adanya modul elektronik diharapkan siswa dapat mengoptimalkan cara belajarnya secara individual/mandiri untuk meningkatkan pemahaman konsep yang dipelajari siswa. Elearning is learning by using the facilities of electronic gadgets, especially computers. The learning procedure is supported by facilities such as computer technology, the internet, audio visual, and graphic media (Surjono \& Patwary, 2015). Modul elektronik yang digunakan dalam pembelajaran harus dirancang oleh guru dengan sangat menarik, seperti guru menampilkan beberapa gambar dan video didalam modul agar siswa tidak merasa bosan dalam proses pembelajaran dan tujuan dari pembelajaran dapat tercapai dengan mudah.

Menurut Muhtadi \& Herawati (2018) E-modul atau elektronik modul adalah modul dalam bentuk digital, yang terdiri dari teks, gambar, atau keduanya yang berisi materi elektroniika digital disertai dengan simulasi yang dapat dan layak digunakan dalam pembelajaran. Dengan adanya modul elektronik ini maka proses belajar menjadi menyenangkan dan diminati baik dari siswa maupun guru yang akan mengajarkannya. Selain itu, modul elektronik mempunyai kelebihan yaitu ukuran file yang relatif kecil sehingga dapat disimpan dalam flash disc, mudah untuk dibawa, bisa digunakan secara offline dapat dipelajari kapan dan dan dimana saja asalkan ada laptop/komputer (Wiyoko, Sarwanto, \& Rahardjo, 2014). Sehingga mengarahkan siswa menuju 
informasi tertentu agar mereka dapat belajar mandiri dengan bantuan atau bimbingan dari guru.

Penggunaan e-modul sebagai bahan ajar yang memanfaatan teknologi bisa mempermudah guru untuk memperkenalkan budaya-budaya yang ada disekitar siswa. Budaya merupakan seperangkat keyakinan, nilai, aturan, norma, symbol, dan tradisi yang dipelajari yang umum bagi sekelompok orang (Asrial, Syahrial, \& Kuriawan dalam Vampa 2017). Dimana guru bisa mengaitkan materi yang dipelajari dengan kearifan lokal dalam proses pembelajaran. Etnokontruktivisme merupakan suatu aliran yang mengarah pada pembentukan pengetahuan siswa dengan menggunakan dan mengintegrasikan nilai-nilai budaya (Asrial, Syahria, \& Kurniawan, 2019). Hal ini bertujuan agar siswa dapat mengetahui kearifan lokal yang ada di daerahnya, kemudian melestarikan nilai-nilai yang terdapat didalamnya.

Pembelajaran yang sukses tidak lepas dari peran seorang guru. Salah satu cara untuk meningkatkannya adalah melalui peningkatan kualitas pembelajaran yaitu dengan pembaharuan, pendekatan atau peningkatan sesuai dengan karakter siswa. The goal is to use tecnologhy to support and facilitate learning and instruction. That is a core task for an educational (Spector, 2013). Siswa dapat aktif dan termotivasi selama proses pembelajaran apabila dituntut untuk dapat berbagi informasi, kerjasama dalam kelompok dan menghargai orang lain. Dalam pembelajaran disekolah, ketika didalam kelas dan di luar kelas kita dapat menjumpai implikasi sosial dari siswa, yaitu kerja sama dan kemandirian didalam kelompok belajarnya (Astaliani, Kurniawan, \& Sumaryanti 2019). Kesenangan dalam belajar pada e-modul adalah rasa suka siswa untuk mempelajari materi kearifan lokal yang dijunjung oleh keingintahuan terhadap pembelajaran etnokontruktivisme.

Penggunaan modul elektronik atau e-modul dipandang lebih efisien dan pendistribusiannya lebih ekonomis. Sehingga perlu dilakukan penelitian untuk mengetahui minat belajar siswa terhadap modul elektronik berbasis etnokonstruktivisme di sekolah dasar.

\section{METODE PENELITIAN}

Desain penelitian yang digunakan adalah desain penelitian deskriptif kuantitatif survei. Penelitian survei adalah prosedur dalam penelitian kuantitatif di mana peneliti mengelola survei untuk sampel atau seluruh populasi yang digunakan untuk menggambarkan sikap populasi, pendapat, perilaku, atau karakteristik khusus (Creswell, 2012). Desain penelitian diterapkan dalam penelitian ini adalah untuk menganalisis minat siswa terhadap modul elektronik berbasis etnokontruktivisme.

Penelitian ini dilakukan di SD Negeri 13/I Muara Bulian dengan jumlah 63 siswa dan SD Negeri 80/I Muara Bulian dengan jumlah 57 siswa. Jadi jumlah populasi pada penelitian ini adalah 120 siswa dengan subjek penelitian siswa kelas V. Data sampel diperoleh dengan menggunakan total sampling. Total Sampling yaitu cara pengumpulan data dengan mengambil elemen atau anggota populasi secara keseluruhan untuk diselidiki (Nasution, 2017). 
Teknik pengumpulan data dalam penelitian ini menggunakan angket. Menurut Cohen, Manion, dan Morrison (2007), kuesioner adalah daftar pertanyaan yang diberikan kepada orang-orang yang bersedia menjawab (responden) sesuai dengan permintaan pengguna. Instrumen angket yang digunakan adalah angket minat dalam belajar menggunakan modul elektronik berbasis etnokonstruktivisme dengan 10 pertanyaan positif. Angket yang digunakan memiliki 5 indikator yang memiliki nilai reliabilitas alpha Cronbach sebesar 0,8.

Pengukuran angket minat menggunakan skala likert. Pilihan jawaban terdiri dari lima pilihan, yaitu Sangat Tidak Setuju dengan skor 1, Tidak Setuju dengan skor 2, Ragu-ragu dengan skor 3, Setuju dengan skor 4 dan Sangat Setuju dengan skor 5. Tingkat angket yang diberikan dapat dilihat pada tabel 1:

Tabel 1. Tingkat Angket Minat terhadap modul elektronik berbasis etnokonstruktivisme

\begin{tabular}{cc}
\hline Kategori & Interval Minat \\
\hline Sangat Baik & $10-18$ \\
Baik & $19-26$ \\
Cukup & $27-34$ \\
Tidak Baik & $35-42$ \\
Sangat Tidak Baik & $43-50$ \\
\hline
\end{tabular}

\section{HASIL DAN PEMBAHASAN}

Hasil dan Pembahasan memuat: what/how, why, dan what else. Hasil penelitian dapat dilengkapi dengan tabel, grafik (gambar), dan/atau bagan. Bagian pembahasan memaparkan hasil pengolahan data, menginterpretasikan penemuan secara logis, mengaitkan dengan sumber rujukan yang relevan. Kemungkinan tindaklanjut kegiatan dapat juga disampaikan pada bagian ini.

\section{Halaman Sampul (Cover)}

Halaman sampul (cover) berisi identitas modul elektronik etnokonstruktivisme.

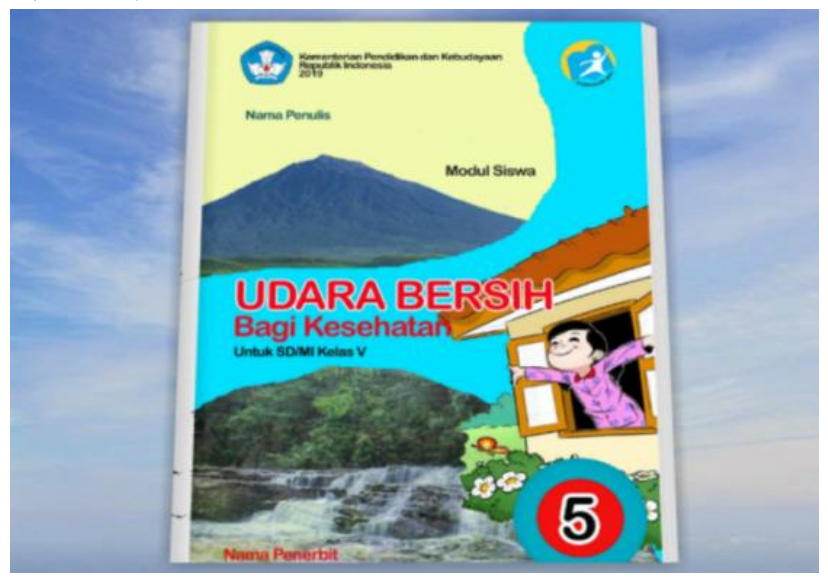

Gambar 1. Halaman sampul depan

\section{Daftar Isi dan Kompetensi Inti}

Daftar isi berisi sub-sub bagian pada modul elektronik etnokonstruktivisme. Sedangkan halaman kompetensi inti berisi empat kompetensi yaitu, kompetensi spiritual 
(KI 1), kompetensi sosial (KI 2), kompetensi pengetahuan (KI 3) dan kompetensi keterampilan (KI 4).

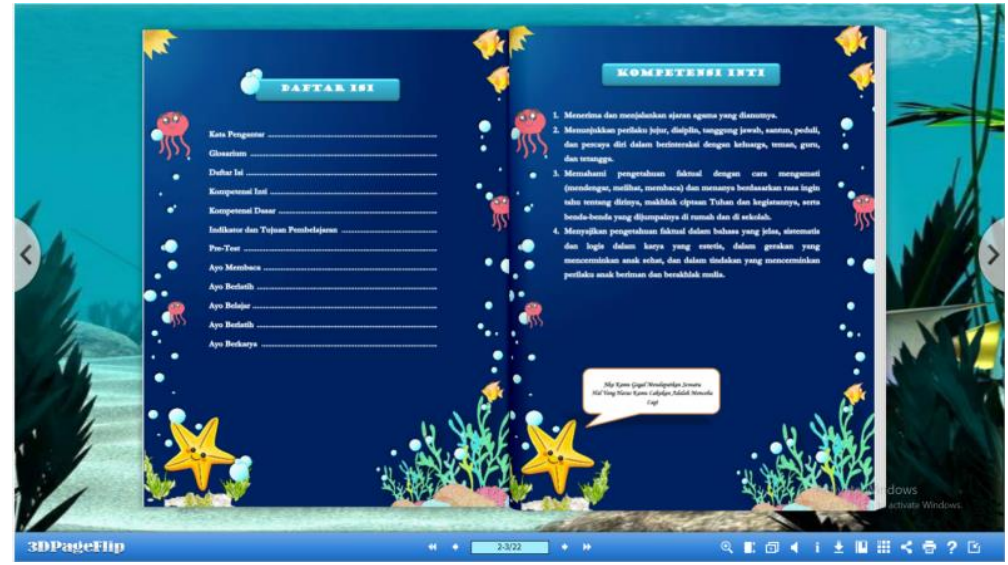

Gambar 2. Halaman Daftar Isi dan Kompetensi Inti

\section{Kompetensi Dasar, Indikator dan Tujuan Pembelajaran}

Kompetensi dasar berisi kompetensi yang harus dikuasai siswa per mata pelajaran. Setiap mata pelajaran memuat kompetensi dasar yang berbeda-beda. Halaman Indikator merupakan pengembangan dari kompetensi dasar, dapat dikembangkan menjadi satu atau beberapa indikator. Sedangkan tujuan pemebelajaran merupakan tujuan dari indikator pembelajaran yang akan dicapai oleh siswa.

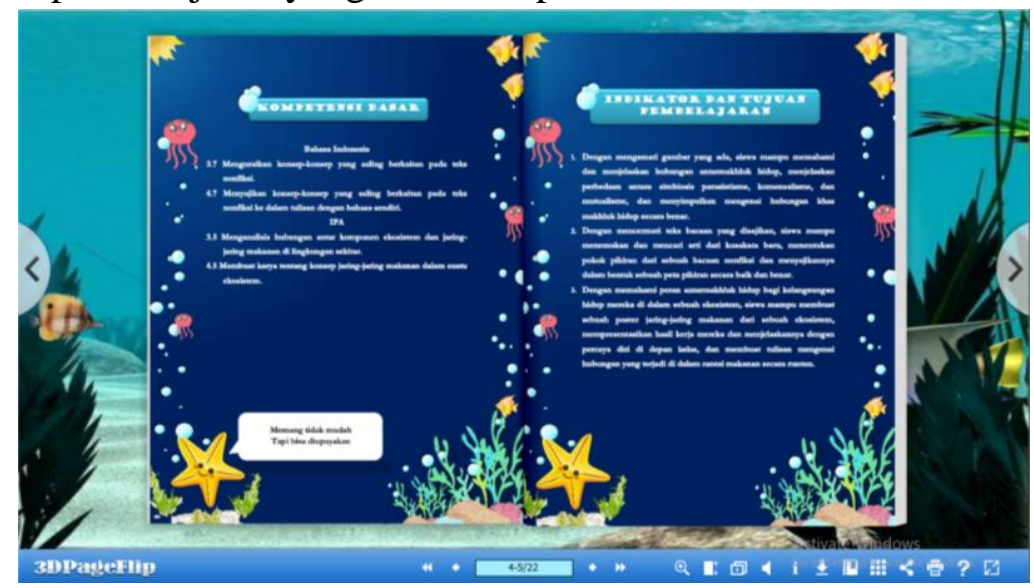

Gambar 3. Halaman Kompetensi Dasar, Indikator, dan Tujuan Pembelajaran

\section{Halaman Pre-test dan Cerita}

Halaman Pre-test digunakan untuk melihat pengetahuan awal siswa. Sedangkan halaman cerita berisi ceritai mengenai salah satu kearifan lokal yang terdapat di daerah yaitu di provinsi Jambi. 


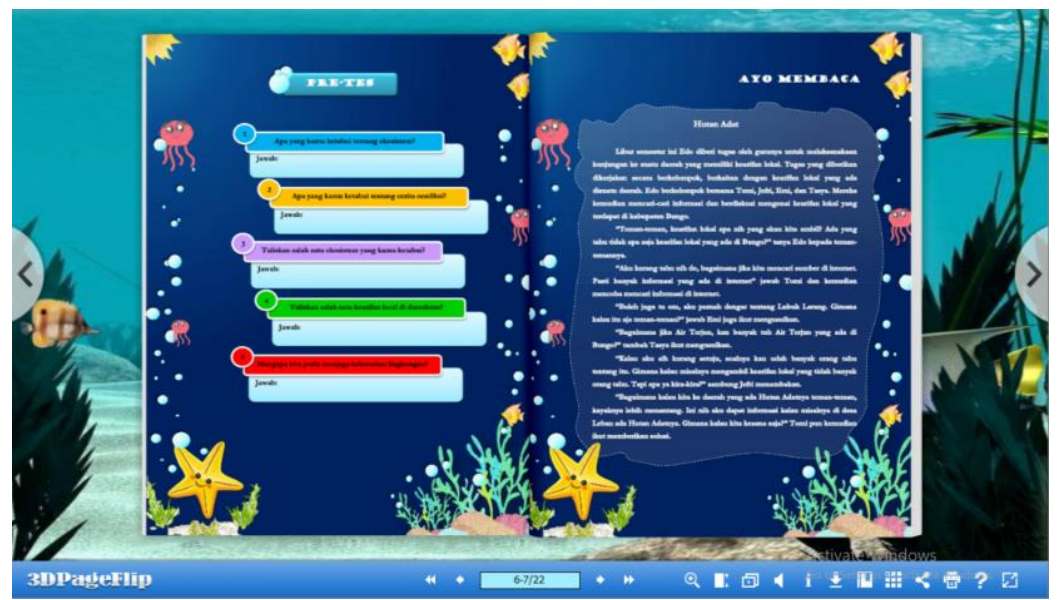

Gambar 4. Halaman Pre-Tes Cerita

\section{Halaman Latihan}

Halaman latihan berisi pertanyaan-pertanyaan berkaitan dengan cerita yang telah tampilkan sesuai penguasaan kompetensi dasar siswa. Halaman soal ini dimaksudkan untuk melatih kemampuan siswa.

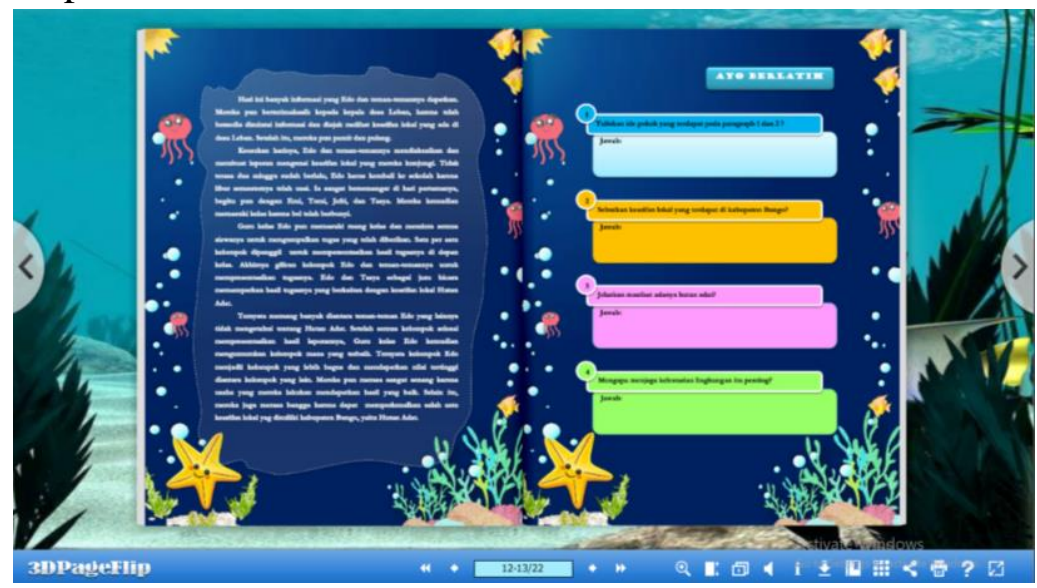

Gambar 5. Halaman Latihan

\section{Halaman Materi Pembelajaran}

Halaman ini berisi muatan materi pembelajaran yang berkaitan dengan cerita yang telah dipaparkan dan sesuai dengan kompetensi dasar yang harus dikuasai siswa.

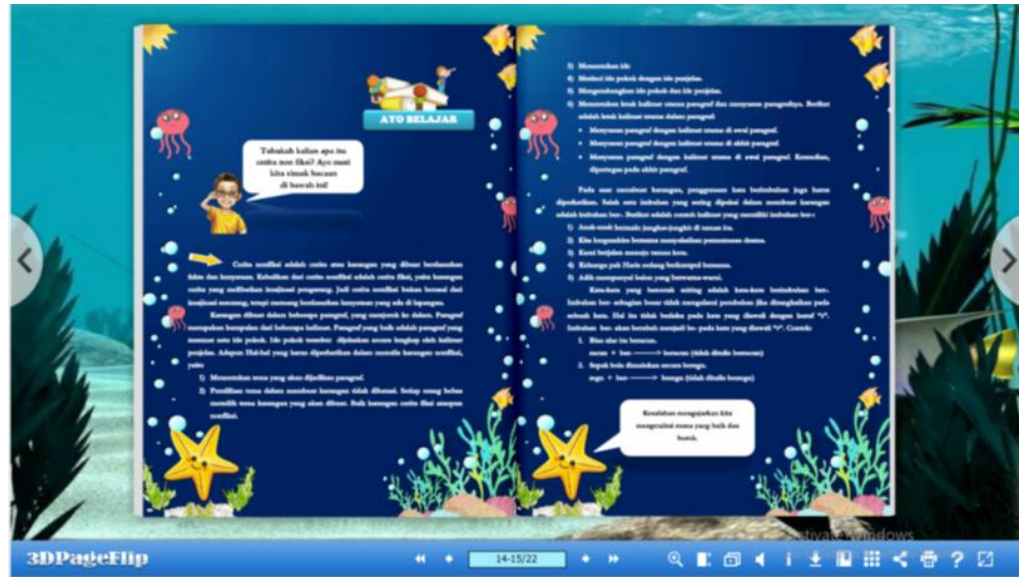




\section{Halaman Prakarya}

Halaman prakarya digunakan untuk melatih keterampilan siswa. Prakarya dilakukan di akhir pembelajaran.

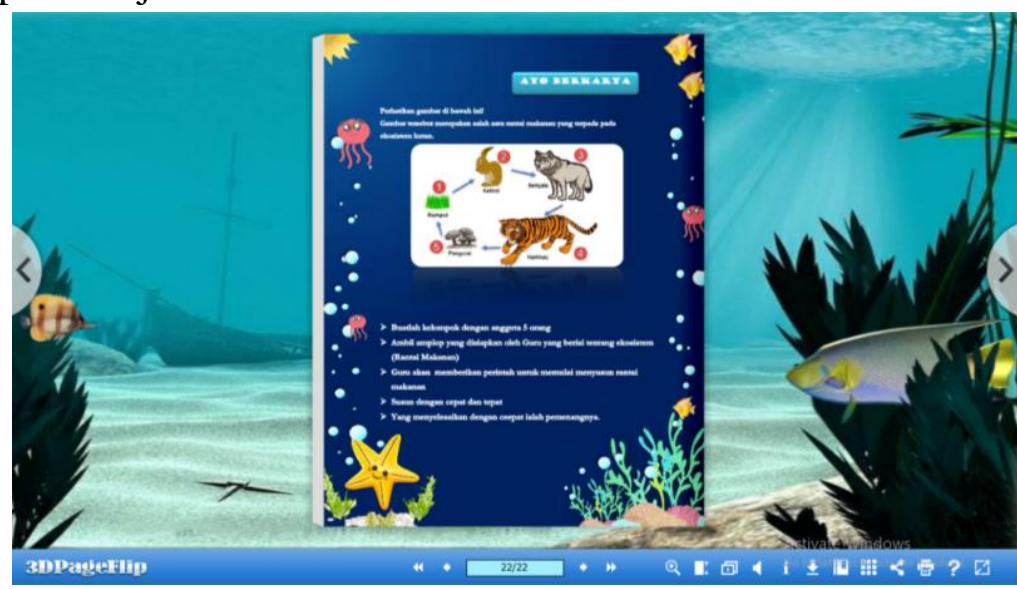

Gambar 7. Halaman Prakarya

Setelah modul elektronik dicobakan di dua sekolah yang berbeda, selanjutnya dilakukan penyebaran angket minat belajar siswa. Perhitungan hasil angket didasarkan pada sekolah masing-masing. Berikut adalah hasil perhitungan angket minat belajar terhadap modul elektronik di SD Negeri No.13/I Muara Bulian:

Tabel 2. Hasil minat belajar siswa SD Negeri No.13/I Muara Bulian

\begin{tabular}{lcccccc}
\multicolumn{1}{c}{ Kategori } & min & max & mean & Std. Dev & F & $\%$ \\
\hline Sangat Tidak Baik & & & & 0 & 0 \\
Tidak Baik & & & & 0 & 0 \\
Cukup & 30 & 50 & 41.42 & 3.89 & 4 & 7.0 \\
Baik & & & & 31 & 54.4 \\
Sangat Baik & & & & 22 & 38.6 \\
\hline \multicolumn{1}{r}{ Jumlah } & & & 57 & 100 \\
\hline
\end{tabular}

Berdasarkan tabel 4. Minat Belajar Siswa SD Negeri No.13/I Muara Bulian diperoleh nilai minimal 30, Maximal 50, Mean 41.42, dan Std.Dev 3.89. Sedangkan pada kategori Sangat Tidak baik dan Tidak Baik memperoleh frekuensi 0 dan presentase sebanyak 0\%. Untuk kategori Cukup memperoleh frekuensi 4 dengan presentase sebanyak 7.0\%, kategori Baik memperoleh frekunsi 31 dengan presentase sebanyak $54.4 \%$, dan kategori Sangat Baik dengan frekuensi 22 dengan presentase sebanyaj $38.6 \%$. Sedangkan hasil perhitungan angket di SD Negeri No.80/I Muara Bulian dapat dilihat pada tabel 3 . 
Tabel 3. Hasil minat belajar siswa di SD Negeri No.80/I Muara Bulian

\begin{tabular}{ccccccc}
\hline Kategori & min & max & mean & Std. Dev & F & $\%$ \\
\hline Sangat Tidak Baik & & & & 0 & 0 \\
Tidak Baik & & & & 0 & 0 \\
Cukup & 31 & 48 & 41.71 & 3.94 & 5 & 7.9 \\
Baik & & & & 27 & 42.9 \\
Sangat Baik & & & 31 & 49.2 \\
\hline Jumlah & & & 63 & 100 \\
\hline
\end{tabular}

Berdasarkan tabel 4. Minat Belajar Siswa SD Negeri No.13/I Muara Bulian diperoleh nilai Minimal 31, Maximal 48, Mean 41.71, dan Std.Dev 3.94. Sedangkan pada kategori Sangat Tidak baik dan Tidak Baik memperoleh frekuensi 0 dan presentase sebanyak 0\%. Untuk kategori Cukup memperoleh frekuensi 5 dengan presentase sebanyak 7.9\%, kategori Baik memperoleh frekunsi 27 dengan presentase sebanyak 42.9\%, dan kategori Sangat Baik dengan frekuensi 31 dengan presentas sebanyak $49.2 \%$.

Hasil dari kedua data ini menunjukkan minat siswa terhadap modul elektronik etnokonstruktivisme mendapat respon positif, artinya modul elektronik tersebut dapat menarik minat belajar siswa sekolah dasar. Menurut (Nurhasanah \& Sobandi, 2016) ketertarikan untuk belajar diartikan apabila seseorang yang memiliki minat terhadap suatu pembelajaran maka, ia akan memiliki perasaan ketertarikan terhadap pelajaran tersebut.

Berdasarkan penginvestigasian dari beberapa hasil perhitungan minat belajar terhadap modul elektronik etnokonstruktivisme yang telah dilakukan, maka dapat dilihat bahwa penggunaan modul elektronik terhadap minat belajar siswa memberikan dampak yang baik. Selain itu, setiap sekolah memiliki minat belajar yang berbeda. Sehingga hal ini dilakukan perhitungan uji $\mathrm{t}$ terhadap kedua sekolah tersebut. Berikut hasil pengolahan data Uji T dengan menggunakan SPSS:

Tabel 4. Hasil Uji T

\begin{tabular}{lcccccc}
\hline & df & $\begin{array}{c}\text { Sig. }(2- \\
\text { Tailed) }\end{array}$ & $\begin{array}{c}\text { Mean } \\
\text { difference }\end{array}$ & \multicolumn{2}{c}{$\begin{array}{c}\text { C5\% Confidence interval of } \\
\text { the Difference } \\
\text { Lower }\end{array}$} & Upper \\
\hline Minat Belajar & 409 & 118 & .683 & .293 & -1.126 & 1.712 \\
\hline
\end{tabular}

Hasil data pada tabel 4 menunjukkan bahwa nilai Sig.(2-Tailed) $0.683>0.05$, maka tidak terdapat perbandingan atau perbedaan yang signifikan pada siswa kelas $\mathrm{V}$ di SD Negeri No.13/I Muara Bulian dengan siswa di SD Negeri No.80/I Muara Bulian. Berdasarakan hasil tersebut dapat dilihat bahwa, siswa di dua sekolah yang dilakukan investigasi memiliki minat belajar dengan adanya modul elektronik. Hasil secara keseluruhan memperlihatkan modul elektronik dapat memicu minat belajar siswa. 
Minat merupakan ketertarikan/kemauan terhadap sesuatu hal, termasuk minat dalam belajar. Minat siswa dalam belajar tidak hanya dipengaruhi oleh mata pelajaran yang tidak disukai, namun dapat juga dari cara mengajar guru dan suasana kelas yang kurang kondusif atau sarana dan prasarana yang ada di sekolah (Jaba, Palittin, \& Nur, 2018). Modul elektronik etnokonstruktivisme dapat menjadi salah satu bahan ajar yang dapat mempengaruhi minat belajar siswa. Siswa akan lebih mudah belajar jika bahan ajar dilengkapi dengan materi, ilustrasi, contoh, dan latihan (Endarwati \& Widjajanti, 2016).

Siswa yang mempunyai minat terhadap suatu subjek tertentu, akan memberikan perhatian yang lebih besar terhadap subjek tersebut (Siagian, 2015). Minat sebagai pernyataan psikis menunjukkan adanya pemusatan perhatian terhadap suatu materi pembelajaran, karena subjek tersebut menarik bagi dirinya (Muldayanti, 2013). Perhatian yang diberikan siswa inilah yang mendorong dirinya untuk mengikuti pembelajaran dengan baik. Siswa yang memiliki minat yang tinggi, maka proses pembelajaran dapat berlangsung dengan aktif.

Proses pembelajaran perlu dibentuk suatu kondisi, agar siswa merasa tertarik, terdorong, dan ingin terus belajar (Firmansyah, 2015; Riwahyudi, 2015). Dengan adanya modul elektronik yang telah dicobakan di dua sekolah yang berbeda dan menunjukkan hasil yang baik, dapat menjadi salah satu cara untuk menarik minat belajar siswa. Minat belajar perlu mendapat perhatian khusus, karena menjadi salah satu faktor penunjuang keberhasilan proses belajar (Pratiwi, 2015). Keberhasilan proses belajar yang baik akan mempengaruhi hasil belajar siswa itu sendiri. Oleh karena itu, minat belajar siswa tidak bisa dianggap suatu hal yang biasa dan perlu untuk diperhatikan dalam proses pembelajaran.

\section{SIMPULAN}

Berdasarkan hasil analisis data dan pembahasan hasil penelitian, maka dapat ditarik kesimpulan bahwa investigasi minat belajar siswa terhadap modul elektronik berbasis etnokonstruktivisme di sekolah dasar SD Negeri 80/1 Muara Bulian dan SD Negeri 13/1 Muara Bulian mendapatkan tanggapan yang positif. Minat belajar siswa terhadap modul elektronik berada dalam kategori Baik dan Sangat Baik. Hasil tersebut menunjukkan bahwa modul elektronik yang dicobakan dapat menarik minat belajar siswa di sekolah dasar pada beberapa sekolah. Oleh karena itu, dengan adanya modul elektronik siswa dan guru dapat membuat kondisi belajar yang baik dan mampu menghasilkan hasil belajar yang lebih baik. 


\section{DAFTAR PUSTAKA}

Ardana I K,. (2019). Penerapan Model Pembelajaran Discovery Learning Untuk Meningkatkan Motivasi Dan Prestasi Belajar Prakarya Dan Kewirausahaan Siswa. Jurnal Ilmiah Pendidikan dan Pembelajaran. 3(1), 1-8.

Asrial, Syahrial, Kurniawan, D.A. (2019). Ilmu Dasar Pembelajaran Etnokonstruktivisme. Jambi: Salim Media Indonesia

Astalini, Kurniawan, D.A, Putri, A.D. (2018). Identifikasi Sikap Implikasi Sosial Dari Ipa, Ketertarikan Menambah Waktu Belajar Ipa, Dan Ketertarikan Berkarir Dibidang Ipa Siswa Smp Se-Kabupaten Muaro Jambi. Jurnal Ilmiah Kependidikan. 7(2), 93-108

Astalini, Kurniawan, D.A, Sumaryanti. (2018). Sikap Siswa Terhadap Pelajaran Fisika Di Sman Kabupaten Batanghari. Jurnal Ilmu Pendidikan Fisika. 3(2), 59-64

Cohen, L., Manion, L., and Morrison, K., Research methods in education, USA and Canada: Routlege, 2007.

Creswell. (2012). Educational Research. University of Nebraska: Karen Mason

Darmaji, Kurniawan, D.A., Suryani, A. (2019). Effectiveness of Basic Physics II Practicum Guidelines Based On Science Process Skills. Jurnal Ilmu Pendidikan Fisika. 4(1), 1-7, ISSN: 2477-5959.

Darmaji, Kurniawan, D.A., Suryani, A., Lestari, A. (2018). An Identification of Physics Pre-Service Tearchers' Science Process Skills Through Science Process Skilss-Based Practicum Guidebook. Jurnal Ilmiah Pendidikan Fisika. 7(2), 239245, ISSn: 2303-1832

Endarwati, E.D., Widjajanti, D.B. (2016). Peningkatan Motivasi Belajar dan Prestasi Belajar Operasi Hitung Bilangan Bulat Siswa Kelas 4 Melalui Media Visual Interaktif. Jurnal Penelitian Ilmu Pendidikan. 9(1), 53-69.

Firmansyah, D. (2015). Pengaruh Strategi Pembelajaran dan Minat Belajar Terhadap Hasil Belajar Matematika. Jurnal Pendidikan UNSIKA. 3 (1), 34-44 ISSN 23382996

Herawati, N.S., Muhtadi, A. (2018). Pengembangan Modul Elektronik Interaktif pada Mata Pelajaran Kimia Kelas XI SMA. Jurnal Inovasi Teknologi Pendidikan. 5 (2), 180-191. ISSN: 2407-0963

Jaba, I., Palittin, I.D., Nur, A.S. (2018). Hubungan Minat Belajar dengan Prestasi Belajar Fisika Siswa Kelas XI IPA SMA Negeri 2 Merauke. Jurnal Magistra. 5(1), 60-68,doi:http://ejournal.unmus.ac.id/index.php/magistra/article/view/723 
Muldayanti, N.D. (2013). Pembelajaran Biologi Model STAD dan TGT Ditinjau dari Keingintahuan dan Minat Belajar Siswa. Jurnal Pendidikan IPA Indonesia. 2(1), 12-17.

Nasution, R. (2017). Teknik Pengambilan Sampling. Fakultas Kesehatan Masyarakat Universitas Sumatera Utara. 1, 1-17

Nurhasanah, S., Sobandi, A. (2016). Minat Belajar Sebagai Diterminan Hasil Belajar Siswa. Jurnal Pendidikan Manajemen Perkantoran. 1 (1), 128-135.

Patwary, M.A.H., Surjono, H.D. (2015). The Implementation of E-Learning with Team Builder at Vocational High Schools. Research and Evaluation in Education Jounal. 1(1), 25-44. e-ISSN: 2460-6995

Pratiwi, N.K. (2015). Pengaruh Tingkat Pendidikan, Perhatian Orang Tua, dan Minat Belajar Siswa terhadap Prestasi Belajar Bahasa Indonesia Siswa SMK Kesehatan di KotaTangerang. Jurnal Pujangga. 1 (2), 75-105.

Riwahyudin, A. (2015). Sikap Siswa dan Minat Belajar Siswa Terhadap Hasil Belajar IPA Siswa Kelas V Sekolah Dasar di Kabupaten Lamandau. Jurnal Pendidikan Dasar. 6(1), 11-23.

Rusman. (2014). Meningkatkan Prestasi Belajar IPA Melalui Model Pembelajaran Kooperatif Think-Pairs-Share (TPS). Jurnal PEDAGOGIA. 3(1), 67-79.

Siagan, R.E.F. Pengaruh Minat dan Kefbiasaan Belajar Siswa terhadap Prestasi Belajar Matematika. Jurnal Formatif. 2(2), 122-131. ISSN 2088-351X

Spector, J.M. (2013). Trends And Research Issues in educational Technology. The Malaysian Online Journal of Educational Technology. 1(3), 1-9.

Wiyoko, T., Sarwanto., Rahardjo, D.T. (2014). Pengembangan Media Pembelajaran Fisika Modul Elektronik Animasi Interaktif Untuk Kelas XI SMA Ditinjau Dari Motivasi Belajar Siswa. Jurnal Pendidikan Fisika. 2(2), 11-15. ISSN: 23380691. 
